\title{
A importância da memória institucional e o CEHVAP (Centro de História e Memória da UNIVAP)
}

\begin{abstract}
Maria Helena Alves da Silva*
Maria Aparecida Chaves Ribeiro Papali ${ }^{\star *}$

Valéria Zanetti***

Palavras-chave:

Universidade

Memória Institucional

Centro de História e Memória

Resumo: Este trabalho tem como objetivo explorar e discutir a importância da memória institucional dentro e fora da Universidade do Vale do Paraíba (UNIVAP), localizada na cidade de São José dos Campos/SP, entendendo qual a importância da instituição e de seu Centro de História e Memória (CEHVAP) no contexto da criação da Universidade e na história da cidade, e levantando a questão de por que o Centro tenha tão pouco reconhecimento por parte dos outros setores da Universidade apesar de ser oficialmente reconhecido como estratégico e indispensável para o funcionamento da instituição e manutenção de sua história. Para discutir sobre o Centro de História e Memória da UNIVAP, o CEHVAP, será feita uma breve explanação sobre os fatos que levaram à criação de seu primeiro curso e a criação da Universidade, utilizando entrevistas realizadas pelo Centro que nos mostraram que, embora seja mostrado apreço e reconhecimento pela instituição, a sua importância na história da cidade e para os seus habitantes, ainda falta o sentimento de pertencimento à instituição, que pode ser melhorado através de canais de comunicação com a sociedade e com o acesso a seu acervo histórico e de memória.
\end{abstract}

Keywords:

University

Institucional Memory

Center of History and Memory

Abstract: This work aims to explore and discuss the importance of institutional memory inside and outside University of Vale do Paraíba (UNIVAP), located in the city of São José dos Campos/SP, understanding the importance of the institution and its History and Memory Center (CEHVAP) in the context of the creation of the University and in the history of the city, and raising the question of why the Center has so little recognition on the part of the other sectors of the University despite being officially recognized as strategic and indispensable for the functioning of the institution and maintenance of its history. To discuss the Center for History and Memory of UNIVAP, CEHVAP, a brief explanation will be made of the facts that led to the creation of its first course and the creation of the University, using interviews conducted by the Center that showed us that although appreciation and recognition by the institution are show, along as its importance in the history of the city and its inhabitants, still lack the feeling of belonging to the institution, which can be improved through channels of communication with society and access to its historical and memory heritage.

Recebido em 20 de outubro de 2016. Aprovado em 30 de janeiro de 2017.

\section{Introdução}

Criado em 2011, o Centro de História e Memória (CEHVAP) da Universidade do Vale do Paraíba (UNIVAP) tem como objetivo a gestão documental e a reconstrução do processo histórico que levou à criação da UNIVAP, em São José dos Campos. Contando com mais de 45.600 fotografias, 5 mil documentos, 80 horas de entrevistas quase 80 horas de vídeo, o CEHVAP oferece ao público documentos digitalizados e identificados; no entanto, é pouco conhecido dentro do meio universitário.

\footnotetext{
* Graduada em História, mestranda no Programa de Pós-Graduação em Mestrado em Planejamento Urbano e Regional da Universidade do Vale do Paraíba (UNIVAP). É gestora de documentos do Centro de História e Memória (CEHVAP) da UNIVAP. E-mail: maria.42246@yahoo.com.br ** Possui graduação em História pela Universidade do Vale do Paraíba (UNIVAP), concluiu Mestrado em História do Brasil na Pontifícia Universidade Católica de São Paulo (PUC), em 1996, e o Doutorado em História Social também na PUC em 2001. Atualmente, é professora doutora da Universidade do Vale do Paraíba, atuando na Graduação (Curso de História e Geografia) e na Pós-Graduação, como docente permanente do Mestrado em Planejamento Urbano e Regional, na Linha de Pesquisa "Sociedade, Espaço e Cultura". É coordenadora do Núcleo de Pesquisa "Pró-Memória São José dos Campos", do Laboratório de Pesquisa e Documentação Histórica/ IP\&D/UNIVAP e do Centro de História e Memória (CEHVAP) da UNIVAP. E-mail: papali@univap.br

*** Possui graduação em História pela Universidade Federal de Ouro Preto (1988) mestrado em História pela Pontifícia Universidade Católica do Rio Grande do Sul (1994) e doutorado em História Social pela Pontifícia Universidade Católica de São Paulo (2008). É professora e pesquisadora da Universidade do Vale do Paraíba (UNIVAP) atuando na graduação (Curso de História e Geografia) e como docente permanente do Mestrado e Doutorado em Planejamento Urbano e Regional da UNIVAP. É coordenadora do Núcleo de Pesquisa Pró-Memória São José dos Campos, do Laboratório Cidade e Memória e colaboradora do CEHVAP (Centro de História e Memória da UNIVAP). E-mail: zanetti@univap.br
} 
Este trabalho tem como objetivo explorar e discutir a importância da memória institucional dentro e fora da UNIVAP, entender qual a importância da instituição e de seu Centro de História, trabalhando também a falta de reconhecimento do seu Centro e quais são os motivos que levam a isso, pois - embora seja reconhecida como uma "informação estratégica, indispensável à gestão e ao planejamento organizacional" (MATOS, 2005 , p. 33) - a memória institucional raramente está articulada e disponível de forma sistemática nas Universidades, tanto públicas quanto particulares. Como observa Maria Teresa Navarro de Britto Matos, a memória institucional "[...] dificilmente é percebida e compreendida como informação estratégica dotada de real valor decisório para as atividades de gestão e planejamento das instituições universitárias" (MATOS, 2005, p. 33). Como notam Ieda Pimenta Bernardes e Hilda Delatorre, o arquivo é, em geral, visto como "uma unidade administrativa menor, sem atribuições bem definidas a não ser 'guardar papéis" e, não tendo reconhecimento, é conduzida muitas vezes ao desprestígio e à desvalorização de seus serviços, decorrendo na falta de "recursos materiais e humanos com qualificação técnica adequados ao seu pleno funcionamento" (BERNARDES; DELATORRE, 2008, p. 7).

Ainda para Matos, nas universidades existe um silêncio sobre a sua memória institucional, sendo este considerando um saber "clandestino" dentro da própria instituição, habitando no limbo e dotada apenas de um prestígio simbólico (MATOS, 2005, p. 35). Em relação aos acervos de memória da Universidade Federal da Bahia (UFBA), Matos acredita que a memória institucional sempre precisou ter a sua relevância assegurada e de atenção institucional formal, uma vez que tem grande importância no reconhecimento da instituição:

A demonstração de que a memória institucional possui um papel de destaque na consolidação de uma identidade institucional é muito comum. $\mathrm{O}$ impacto que a memória institucional possui sobre a cultura da instituição é incansavelmente propalada. Contudo, todo o prestígio atribuído à memória institucional não passa ao ato, dificilmente se realiza em uma medida organizacional concreta. Ou seja, a memória institucional possui imenso valor e reconhecimento simbólico na instituição universitária, o que parece não ser o suficiente para um aproveitamento orgânico e sistêmico dos acervos de memória. (MATOS, 2005, p. 37)

Da mesma forma, como observam Rueda, Freitas e Valls (2011), muitas vezes as instituições criavam locais para a preservação da memória institucional, no entanto, muitas vezes os setores acabavam sendo desativados por motivos financeiros, falta de planejamento ou de gestão e os setores de Memória Institucional acabavam depositados em galpões. No entanto, com a conscientização da importância da memória institucional, com o surgimento de diversos Centros de memória nas Universidades brasileiras, "[...] as instituições perceberam que era preciso promover mudanças organizacionais necessárias sem perder a sua identidade" (RUEDA; FREITAS; VALLS, 2011, p. 86).

Como observa Glezer (1989, p. 32), enquanto os arquivos estiveram associados, “[...] em nossas idéias [sic], com o acúmulo de papéis velhos, não mais úteis, local de espaço perdido [...] muito pouco poderá ser concretizado na área de prestação de contas à sociedade dos recursos investidos". Para a autora, a preservação e a organização de um acervo documental universitário representam uma iniciativa de a Universidade prestar contas à sociedade, de forma que a sua inexistência prejudica "[...] o desenvolvimento do conhecimento científico, o processo de formação de pesquisadores iniciantes, a exigência da ética da pesquisa, o rigor diante da propriedade intelectual” (GLEZER, 1989, p. 32).

\section{A criação da "tão desejada Universidade”}

Em 1921, a cidade de São José dos Campos entrou na economia industrial com o 
estabelecimento da Cerâmica Bonádio, a Fábrica de Louças Santo Eguênio; seguindo em 1922 com a Cerâmica Santa Lúcia; em 1925 com a Tecelagem Paraíba; em 1942 a Cerâmica Weiss e em 1946 a Rhodia Indústrias Químicas e Têxteis. Em 1950, foi inaugurada a Rodovia Presidente Dutra e, como observou uma monografia estatística corográfica de São José dos Campos em 1977, foi nessa época que teve início a vida Universitária na cidade, com a instalação do Instituto Tecnológico Aeronáutico (ITA) (MATIAS, 1977, volume III, p. 16); para Amilton Maciel Monteiro (1997, p. 9), essa vinda do Centro Técno Aeroespacial (CTA), onde fica o ITA, "revolucionou a vida cultural de São José dos Campos", com diversos técnicos e professores vindo para a cidade, a qual passou a ter "centenas das melhores cabeças jovens do País, na condição de estudantes de engenharia”.

No entanto, para que pudessem atingir "um desejado equilíbrio intelectual" (entre os alunos do ITA e os joseenses), sentiu-se a necessidade de criar uma Faculdade com um curso superior voltado para a área de humanas, "de modo a oferecer novas opções de estudo à juventude joseense e valeparaibana" (MONTEIRO, 1997, p. 32). No entanto, decidiu-se criar um Curso de Direito: essa mudança pode ter sido feita porque, como observou o engenheiro Henry Maksoud (1970, p. 26), as faculdades de Direito não exigiam investimentos em instalações de laboratórios ou equipamentos específicos necessários para o seu funcionamento. Em 1954, o presidente Getúlio Vargas concedeu a autorização para o funcionamento do curso de Bacharelado na Faculdade de Direito do Vale do Paraíba.

Cinco anos depois, seria criado o Instituto Valeparaibano de ensino (IVE), que tinha como objetivo instalar, manter e criar na cidade de São José dos Campos estabelecimentos de ensino (superior, secundário, normal e primário) e cursos visando, dessa forma, a "[...] oferecer maiores oportunidades de estudo, principalmente à juventude da região do Vale do Paraíba" (MONTEIRO, 2002, p. 38-39). Em 1963, com o objetivo de facilitar a criação de novos cursos, a Instituição foi transformada em Fundação. Sempre funcionando ao lado do poder público, com doações de terrenos, incentivos fiscais e doação para a construção de prédios, em 1968 começou-se a almejar a criação de uma universidade no Vale do Paraíba. Em uma carta escrita pelo prefeito Joaquim Bevilacqua para o Presidente da Câmara Municipal, José Luiz Carvalho de Almeida, em 13 de maio de 1982, constata-se que:

[...] entre as demais cidades do Estado e do País, pela avançada e sofisticada mão de obra [sic] ocupada pelas suas indústrias e pelos seus centros de pesquisa, não pode, como "Capital da Tecnologia", ver-se privada de conquistar a sua Universidade, não só reunindo num conglomerado todos os cursos já existentes na FVE, mas igualmente outros indispensáveis à criação dessa Universidade. E, fora qualquer dúvida ou cogitação é a Fundação Valeparaibana de Ensino, quer pelo seu passado, pelo seu presente ou mesmo pelo destino grandioso que lhe reserva o futuro, a entidade que poderá, com o esforço conjugado de todas as forças vivas do Município, proporcionar o alcance já próximo e antevisto dessa meta que deve ser procurada, qual seja, repito, a criação de nossa Universidade, a par de instalações mais próprias e adequadas ao seu melhor e mais eficiente funcionamento. (MONTEIRO, 2002, p. 79).

Em 1992, por meio da Portaria MEC n 510, de $1^{\circ}$ de abril de 1992, autorizou-se a criação da Universidade do Vale do Paraíba (UNIVAP), que reuniria em seu novo campi, no Bairro Urbanova, em São José dos Campos, todos os cursos superiores mantidos pela Fundação Valeparaibana de Ensino (FVE), que substituíra a IVE.

\section{Centro de História e Memória (CEHVAP) da UNIVAP}

Como observam Boso et al. (2007, p. 125), o boom da Arquivologia científica no Brasil aconteceu na década de 1970, quando diversos congressos, eventos, publicações, cursos e a valorização do arquivista aconteceu. Já para Seffrin et al. ([s. d.], p. 1) as iniciativas de organização e sistematização de arquivos universitários no Brasil surgiram na 
década de 1980, "[...] quando as universidades começaram a despertar para as questões da organização e do estabelecimento" da memória da Universidade. Curiosamente, foi justamente na década de 1980 que surgiu o primeiro projeto para instalação de um "Centro de Documentação Histórica" na Universidade do Vale do Paraíba, do curso de Planejamento Educacional. Como observou a autora Maria Aparecida Nogueira dos Santos, então bibliotecária-chefe da Biblioteca Central da Universidade,

Uma instituição de ensino como a Fundação Valeparaibana de Ensino, não pode, nem deve ficar indiferente sobre a inexistência de informações sobre acervos documentais brasileiros [...] nossa F.V.E., também poderia criar o seu Centro de Documentação Histórica, dando ao país a São Paulo, ao Vale do Paraíba e a São José dos Campos, a sua contribuição já que possui tantos motivos para se orgulhar daqueles que transpuzeram os portais dessa casa. (SANTOS, 1980, p. 4).

Os objetivos desse "Centro de Documentação Histórica" eram:

a) Contribuir para o estudo e a pesquisa dos alunos de todas as unidades de ensino;

b) Dar assistência e amparo às pesquisas dos estudiosos da nossa história, que fazem parte da nossa comunidade.

c) Criar novos interesses para a nossa mocidade tão carente de apoio em suas iniciativas e tão confiantes nos seus mestres e administradores;

d) Propiciar a Professores especialistas, particularmente, de algumas universidades se orgulham de serem autoridade tanto na especialidade, quanto na literatura respectiva [...]. A melhor maneira de entabular uma troca de informações, talvez seja levar ao leitor um artigo que certamente o interessará e que tenha sido publicado numa revista, que ele jamais pensaria em consultar.

[...] e) Propiciar também a especialistas fontes primárias de pesquisa. (SANTOS, 1980, p. 5).
Com uma proposta muito interessante, esse Centro nunca foi criado na Universidade, e tal proposta nunca havia sido comentada e nem publicada pela Universidade; e é justamente por conta desse tipo de documento que levou o Centro de História da UNIVAP a ser criado: o documento estava guardado, em um armário, na Secretaria Geral da Universidade, onde ninguém além de seus funcionários tinha acesso (e nem mesmo eles tinham uma catalogação exata do que havia no armário). Ainda hoje, esse documento se encontra lá, tendo o CEHVAP conseguido permissão apenas para tirar uma cópia do documento. É curioso que o tal Centro de Documentação Histórica tenha praticamente os mesmos objetivos que o CEHVAP, que seria criado pelas professoras Maria Aparecida Papali e Valéria Zanetti exatos 21 anos depois sem que nenhuma delas tivesse conhecimento dessa proposta.

Até o momento, o CEHVAP conta com centenas de documentos identificados nas categorias de trabalhos de alunos, comunicados oficiais, relatórios de cursos, chamadas de sala de aula, provas e regimentos, e mais de 5 mil documentos não identificados de processos jurídicos, comunicados e relatórios oficiais e estudos que nunca antes estiveram à disposição do público. Como observa Glezer, a falta desses documentos, relacionados a trabalhos de alunos, cursos e disciplinas, prejudica o processo de formação do pesquisador, uma vez que a falta de um arquivo dificulta $o$ acesso a essas informações (GLEZER, 1989, p. 32). Para a autora, embora muito seja falado de "prestação de contas à sociedade", enquanto o produto da atividade universitária ficar oculto, ou guardado de forma inacessível, pouco irá se resultar dessa prestação de contas (GLEZER, 1989, p. 33). Além disso, enquanto estiver voltada para o saber científico, a Universidade

[... deve ter por meta o desenvolvimento do conhecimento por meio da pesquisa, a transmissão do conhecimento por meio do ensino, a preservação do conhecimento e a difusão do conhecimento por meio da publicação. Nesse sentido, a função do 
Arquivo Universitário é extremamente importante na vida acadêmica dos alunos e da Universidade. (BOSO et al., 2007, p. 123-124).

Quanto à divulgação dos conhecimentos do Arquivo por meio da publicação, os funcionários e estagiários do CEHVAP já publicaram diversos artigos e participaram de congressos sobre seus documentos; entre eles, publicados recentemente, encontram-se os artigos "A Ditadura e os movimentos estudantis na Fundação Valeparaibana de Ensino (1964-1985)", apresentado do XIX INIC; o artigo "Centro de História e Memória da UNIVAP - CEHVAP", apresentado no $15^{\circ}$ Congresso Nacional de Iniciação Científica do CONICSEMESP, e os artigos "Arquivo morto ou Centro de História? Um breve estudo sobre a importância do cotidiano escolar para a pesquisa" e "A Universidade do Vale do Paraíba como patrimônio da cidade de São José dos Campos” que foram aceitos para apresentação oral e em banner para o XX INIC e XVI EPG da UNIVAP. Embora no artigo do Congresso do CONIC tenha sido explorado unicamente o CEHVAP e as suas funcionalidades, na elaboração do artigo do XIX INIC exploramos os movimentos estudantis praticados pelos estudantes da UNIVAP, para o qual utilizamos entrevistas concedidas ao CEHVAP, e um documento que está em seu arquivo e que foi emitido pelo Ministério do Exército dirigido à Fundação Valeparaibana de Ensino, mantenedora da futura UNIVAP, pedindo a expulsão de três alunos da Faculdade de Filosofia em 1969. Os alunos eram considerados "nocivos [...] ao ambiente da Faculdade", procuravam "atuar politicamente", desse modo "agitando e subvertendo a Faculdade de Filosofia".

Dessa forma, podemos constatar que quando uma informação histórica está disponível ao público em geral, a pesquisadores e estudantes, ela proporciona não só o acesso “[...] à história da instituição como também à sua trajetória de atuação e a sua relação com a comunidade onde está inserida" (MANINI; MARQUES, 2007, p. 2). Utilizando-se da tecnologia, ainda é possível que as informações de um Centro de Memória esteja disponível ao público “[...] em qualquer lugar do mundo, além de fomentarem a interação das instituições, seus produtos, serviços e objetos de pesquisa junto à sociedade" (MANINI; MARQUES, 2007, p. 2).

\begin{abstract}
Ações como a criação de um Centro de Memória, seja ele físico ou virtual, permitem o aprendizado de questões que são essenciais no presente $\mathrm{e}$ que podem ser potencializadas a partir do acesso dos pesquisadores às fontes históricas e da produção acadêmica relacionada ou embasada no acervo. Somente com o uso efetivo e a disseminação, por diversos meios de comunicação, dos objetos, documentos e informações de caráter histórico é possível entender a trajetória da sociedade até os dias atuais. (MANINI; MARQUES, 2007, p. 9).
\end{abstract}

Ainda para os autores Manini e Marques (2007, p. 5), a necessidade da preservação da memória da instituição não é restrita apenas aos documentos tradicionais: assim como as bibliotecas e os museus, os arquivos e os centros de memória passaram a valorizar os programas de história oral. Como notam Moura e Souza (2011), as lembranças sempre diferem da realidade, carregando as contingências e circunstâncias do momento, podendo também ser transmitidas, reproduzidas e estimular questionamentos. Além disso - mesmo com o desenvolvimento de mecanismos tecnológicos encontros pessoais e o diálogo -, "são as formas mais adequadas à reprodução de memórias individuais e coletivas" (p. 372-373). Como observam os autores, a memória é uma abertura às interações sociais, e trabalhar com a memória institucional não é apenas explorar a história vivida pelos alunos e funcionários de uma instituição, mas também "honrar o esforço de todos que contribuíram (e ainda contribuem) para a continuidade da instituição"; ainda para as autoras, os programas de memória e documentação precisam ser norteados e é necessário instituir "[...] determinados fatos para evidenciar, ou seja, são as histórias escolhidas como relevantes que apresentam a organização à sociedade" (MOURA; SOUZA, 2011, p. 371-373). 
Nesse sentido, o CEHVAP também promove o recolhimento de depoimentos de funcionários e alunos ligados à UNIVAP, tendo até o momento entrevistado 80 pessoas. Os depoimentos são gravados no próprio Acervo do CEHVAP ou na sala do depoente, e depois as falas são transcritas, sendo usadas posteriormente para referência e análise de momentos históricos da Universidade. Como nota Fontanelli (2005, p. 36), a utilização dos procedimentos de informática é fundamental para "o desenvolvimento, a valorização e a perpetuação das instituições-memória", de forma que podem ser usadas não somente para a preservação e a disseminação da informação mas para realizar trabalhos que tenham como foco essas premissas.

Assim que o CEHVAP foi criado, em 2011, os estagiários do CEHVAP começaram a publicar artigos utilizando o material disponível no Acervo, comentando também sobre a importância do CEHVAP e publicando-o como forma de adquirir reconhecimento dentro e fora da Universidade. Desse modo, destacam-se os artigos "Memória institucional e gestão documental: o centro de História e Memória da UNIVAP/FVE (CEHVAP)", publicado no INIC de 2012, e comentando também sobre uma exposição feita na entrada da Faculdade de Educação e Artes, também em 2012, sobre os 40 anos do curso de História, e que prometia que o CEHVAP, posteriormente, digitalizaria e disponibilizaria, fosse por meio material ou virtual, toda a documentação do acervo tendo como objetivo "facilitar o acesso da população a informações sobre a história da universidade" através de um link no site da universidade, onde poderiam ser feitas pesquisas (VIANA et al., 2012, p. 3).

Foram necessários cinco anos para que todo o acervo de fotografias do CEHVAP, atualmente com 46 mil fotos, fosse digitalizado; e, até o momento, foram identificados mais de 4 mil documentos; apenas em 2015. Também foi criado um link no site da Universidade para divulgar o CEHVAP. Por isso, em 2016, já se planejava, juntamente com o CTIC e o Marketing, um meio de identificação e pesquisa de documentos, por meio do qual o usuário poderia se informar quais documentos o CEHVAP tem em seu Acervo.
Junto das atividades do CEHVAP também está o desenvolvimento de seu Acervo de História oral, que contém hoje mais de 70 entrevistados. Em seus discursos, é possível notar que eles acreditam na relevância da preservação da memória da Universidade, e quando falam da sua importância relacionando-a com a cidade, quase sempre referenciam a história da Universidade com a do município. Como observou a Entrevistada A, então diretora da Faculdade de Ciências da Saúde da UNIVAP e que havia chegado à cidade de São José dos Campos em 1977, sendo contratada pela Universidade em 2001:

Confesso que, embora morasse aqui em São José dos Campos há muitos anos, eu não conhecia o campus Urbanova da UNIVAP. Foi uma grande surpresa para mim, morando há mais de 20 anos na cidade conhecer esse campus. Assim como eu não conhecia esse local e toda a sua dimensão, acho que é importante que a gente divulgue não só a história, mas a UNIVAP como um todo, mostrando realmente o que ela tem de riqueza em termos de pessoas que aqui trabalham, que se dedicam com muito afinco, com muito amor, para que a instituição seja reconhecida e para mostrar que os profissionais que aqui atuam apresentam excelente desempenho. (ENTREVISTA A, 2012, p. 1).

A Entrevistada B, ex-professora do curso de História da UNIVAP que foi contratada em 1972, observou não só a importância da sua História mas também a sua identificação como um patrimônio da cidade e da região:

É uma coisa importante. Eu não sei qual é o tamanho da UNIVAP hoje; mas, apesar de haver muita concorrência hoje, porque eu acho que ela foi também, talvez até mais significativa na época em que ela foi criada, que ela revolucionou aqui a cidade. Eu não participei da primeira fase da UNIVAP quando ela foi criada, porque era outro grupo que criou a Fundação Valeparaibana de Ensino. Mas ela foi politicamente muito importante. E ela agitou a cidade, porque São José na época, década de 60 , 70 , era ainda bem pequena. A cidade 
começou a crescer na década de 50 com a Embraer, o ITA [...]. Depois, ela passa por esse período de crescimento. E só em fins de 70, começo de 80 é que ela tem esse crescimento econômico muito grande. Então, a UNIVAP, de uma certa forma, está nessa primeira fase de crescimento da cidade de São José dos Campos [...]. Hoje ela é um patrimônio importante, não só da cidade, como aqui da região. Acho que o que precisa na UNIVAP é os alunos parecessem mais. A gente quase não sabe dos alunos. E essa iniciativa de vocês eu acho importante. (ENTREVISTA B, 2012, p. 3).

Para a Entrevistada F, ex-aluna do curso de Geografia da turma de 1994, e com mestrado em Planejamento Urbano e Regional pela UNIVAP, e docente da Universidade desde 1998, é possível reconhecer a Universidade em seu contexto regional não apenas por sua influência no desenvolvimento do município, mas pela influência de seus ex-alunos na cidade:

A UNIVAP é uma universidade, uma instituição reconhecida aqui no Vale do Paraíba. Acho que a participação da UNIVAP no Vale é muito importante. $\mathrm{Na}$ minha tese, inclusive, coloco a UNIVAP como uma das instituições criadas em São José dos Campos que contribuíram para o desenvolvimento científico, tecnológico e a produção de conhecimento. Vejo que a UNIVAP cumpre esse papel. [...] Vejo a UNIVAP com um papel muito importante para o desenvolvimento da região. (ENTREVISTA F, 2011, p. 2).

Como observam Goulart, Perazzo, Lemos (2005, p. 160), a preservação e o registro da memória deve se tornar uma preocupação da sociedade, pois “[...] incentivar e oferecer condições para rememoramento da memória individual, em busca da preservação da memória coletiva" nos permite registrar os apagamentos e ocultamentos além do que parece estar momentaneamente no esquecimento. A memória, como notam os autores, faz com que o sujeito se sinta um agente social e histórico, garantindo "[...] poder nas relações, resgata sua identidade, cria valores sociais relacionados ao grupo e ao espaço de convivência"
(GOULART; PERAZZO; LEMOS, 2005, p. 160). Dessa forma, é notável que alguns relatos se difiram tanto um do outro no que se refere ao sentimento de pertencimento dos funcionários: enquanto alguns mencionam que se sentem reconhecidos e pertencentes à universidade, outros depoentes contam que nem os alunos, nem os funcionários se sentem parte da Universidade:

Como aqui nós temos reconhecimento dos colegas, dos superiores, e dos alunos, eu vejo como recompensado toda nossa profissão, toda minha profissão[...]. Todo o meu esforço, as minhas brigas [...] quanto à minha profissão, eu vejo pelo reconhecimento principalmente dos colegas, não só aqui da UNIVAP, né? Mas dos profissionais que trabalham em outras instituições. Uma vez que a gente tem o reconhecimento e você vê que as pessoas te respeitam. Você vê que as pessoas respeitam o trabalho que você faz na Instituição e respeitam a Instituição que você trabalha. Então, isso eu acho muito. É compensador! (ENTREVISTA C, 2014, p. 7).

Em entrevista cedida ao CEHVAP, um dos professores-fundadores da Faculdade de Serviço Social de São José dos Campos, instalada em 1969, disse que:

Falta para nós aqui dentro o sentimento de pertencer. Eu pertenço a essa instituição. Eu sou membro dessa instituição. Essa instituição é uma comunidade constituída de uma população, onde essa população tem aluno, tem funcionário, tem professor. É uma comunidade. É uma família [...]. A UNIVAP tem tudo para ser uma das maiores instituições do país. Em termos de estrutura, de área. Precisamos é todo mundo entender que isso é nosso. Não propriedade nossa. Nós somos responsáveis por isso [...]. (ENTREVISTA ?, 2011, p. 7-8).

Já para a docente da Faculdade de Educação e Artes e então diretora do Instituto de Pesquisa e Desenvolvimento (IP\&D), a Universidade pode ser considerada pequena, mas seu reconhecimento é visto por intermédio dos indicadores: 
A UNIVAP é uma instituição pequena. Mas, para a dimensão da instituição, a gente tem reconhecimentos muito bons. A gente tem indicadores muito bons. Números de bolsistas de produtividade [...] A gente aprova muita bolsa de iniciação científica da FAPESP [...]. Uma marca muito boa. Utilizando uma expressão bastante popular, como diz hoje: nós estamos "bem na foto" [risos]. Academicamente, nós estamos muito bem. (ENTREVISTA G, 2011, p. 5-6).

Para um entrevistado, formado em Ciências Econômicas na UNIVAP em 1977 e que veio para a cidade de São José dos Campos em 1951, um dos motivos da falta do sentimento de reconhecimento por parte dos funcionários é a burocratização trazida por um dos reitores da Universidade, que fez a Fundação Valeparaibana de Ensino crescer mas que, ao mesmo tempo, burocratizou a instituição:

[...] burocratizando, ele acabou trazendo alguns comportamentos. Muita gente de fora que não via a UNIVAP e a Fundação como uma coisa assim [...], via pura e simplesmente como um local de trabalho [...], e muitas vezes essas pessoas de fora não tinham [...] não foi o meu caso [...], mas não tinha nem aquela diplomacia de reconhecer que você fez essa coisa crescer. Você tem um vínculo muito afetivo com isso aí. (ENTREVISTA E, 2013, p. 18).

Como nota a autora, citando Aldo de Albuquerque Barreto, as instituições de memória precisam se aproximar da população à sua volta e colaborar com outras instituições para que possa oferecer "serviços básicos que disponibilizem informações dos mais diferentes tipos, desde as utilitárias até as seletivas" (BARRETO, 2000 apud FONTANELLI, 2005, p. 39). Além disso, criando condições para que essa informação seja acessada, o profissional permite que essas informações sejam representadas e que o usuário possa ter acesso a essas informações e se apossar delas, podendo transformá-las em informação (SMIT, 2005 apud FONTANELLI, 2005, p. 40).

Para Fontanelli (2005, p. 44), as instituições deveriam criar canais de comunicação para que todos os segmentos da sociedade reconhecessem suas atividades e missão, podendo usufruir de seus serviços e produtos "a partir, principalmente, do acesso a seus acervos". Dessa forma, os centros de memória, que são responsáveis "pela guarda, preservação e fruição de nosso patrimônio cultural e patrimônio histórico", deveriam ter como objetivo que suas atividades pudessem ser consultados por todos os cidadãos que não só têm acesso direto a seu acervo mas que também deveriam ser responsáveis pela sua preservação (FONTANELLI, 2005, p. 44).

\section{Considerações finais}

Pode-se concluir que, para contribuir com a sociedade, ajudar pesquisadores e divulgar documentos, trabalhos e fotografias, o CEHVAP foi criado para explorar a história da Universidade do Vale do Paraíba, preservar a sua história e, como um Centro de História e Memória, também trabalhar com memória oral mediante entrevistas com funcionários e alunos. Esse projeto contribui para um melhoramento e complemento da História e, também, com outras visões de eventos e participações da Universidade.

No entanto, apesar de sua riqueza de materiais e documentos, assim como outros arquivos universitários, o CEHVAP é pouco explorado e reconhecido pela Universidade, seus alunos e funcionários. Para aprimorar o acesso à sua trajetória e a fim de contribuir para a transparência e a prestação de contas da Universidade à sociedade, é necessário que o acesso ao seu Acervo histórico seja possível não apenas no seu meio físico, mas também através de um site online. Dessa forma, será facilitado o acesso a documentos primários não apenas para pessoas relacionadas diretamente à instituição mas do mundo inteiro. E, ao mesmo tempo, é reforçado o sentimento de reconhecimento e de pertencimento de alunos e funcionários ao verem que sua história faz parte da trajetória da instituição.

\section{Referências}

BARRETO, A. Os agregados de informação memória, esquecimento e estoques de informação. 
Datagramazero: revista de ciência da informação, v. 1, n. 3, jun. 2000. Disponível em: <http://dga.org/ jun.00/Art_01htm>. Acesso em: 17 mar. 2003.

BOSO, A. K.; SOUZA, C. A. da R. de S.; CISNE, C. dos S.; CORADI, J. P. Importância do Arquivo Universitário. Revista ACB: Biblioteconomia em Santa Catarina, Florianópolis, v. 12, n. 1, p. 123-131, jan./jun. 2007.

BERNARDES, I. P.; DELATORRE, H. Gestão Documental Aplicada. São Paulo: Arquivo Público do Estado de São Paulo, 2008.

ENTREVISTA A, cedida ao CEHVAP em 27 de abril de 2012.

ENTREVISTA B, cedida ao CEHVAP em 20 de março de 2012.

ENTREVISTA C, cedida ao CEHVAP em 30 de maio de 2014.

ENTREVISTA D, cedida ao CEHVAP em 7 de outubro de 2011.

ENTREVISTA E, cedida ao CEHVAP em 18 de Setembro de 2013.

ENTREVISTA F, cedida ao CEHVAP em 24 de outubro de 2011.

ENTREVISTA G, cedida ao CEHVAP em 15 de setembro de 2011

FONTANELLI, S. A. Centro de Memória e Ciência da Informação: uma interação necessária. 2005. 106 f. Monografia (Bacharelado em Biblioteconomia) Departamento de Biblioteconomia e Documentação da Escola de Comunicações e Artes, Universidade de São Paulo, São Paulo, 2005.

GLEZER, R. Arquivos Universitários: Para quê?. Trans-in-formação, v. 1, n. 3, p. 29-34, set./dez. 1989. Disponível em: <http://periodicos.puccampinas.edu.br/seer/index.php/transinfo/article/ viewFile/1680/1651>. Acesso em: 2 maio 2016.

GOULART, E.; PERAZZO, P.; LEMOS, V. Memória e cidadania nos acervos de história oral e mídia digital. Em Questão, Brasil, v. 11, n. 1, p.??, 2005. Disponível em <http://www.revistas.univerciencia. org/index.php/revistaemquestao/article/ view/3690/3478>. Acesso em: 6 jun. 2016.

\section{MAKSOUD, H. Projeto de Estruturação e Estudo} de Viabilidade Econômica da Universidade de São José dos Campos - Relatório HE106-R1-770, jul. 1970. [Disponível no Acervo do CEHVAP].

MANINI, M. P.; MARQUES, O. G. Informação Histórica: Recuperação e divulgação da memória do poder judiciário brasileiro. In: ENCONTRO NACIONAL DE PESQUISA EM CIÊNCIA DA INFORMAÇÃO (ENANCIB), 8., 28-31 out. 2007, Salvador. Anais eletrônicos... Salvador: UFBA, 2007. Disponível em: <http://www.enancib.ppgci.ufba.br/ artigos/GT2--149.pdf>. Acesso em: 2 maio 2016.

MATIAS, B. R. Monografia estatístico coreográfica de São José dos Campos - SP. 15-07-1977. 123 p. [Disponível no Acervo do CEHVAP].

MATOS, M. T. N. de. Memória institucional e gestão universitária: o caso da Universidade Federal da Bahia. Cadernos BAD (Revista da Associação Portuguesa de Bibliotecários, arquivistas e documentalistas) - Políticas de Salvaguarda do Património e Memória Digital, n. 2, p. 33-56, 2005. Disponível em: <http://www.bad.pt/publicacoes/ index.php/cadernos/article/view/812/811>. Acesso em: 2 maio 2016.

MONTEIRO, A. M. Elementos históricos da Univap e de seu berço: São José dos Campos. Rascunho de livro enviado à Reitoria de Cultura e Divulgação. São José dos Campos: UNIVAP, 1997. [Disponível no Acervo do CEHVAP].

Elementos históricos da Univap e de seu berço. Pró-Reitoria de Cultura e Divulgação. São José dos Campos: UNIVAP, 2002.

MOURA, C. P. de; SOUZA, A. O. de S. Memória e Comunicação Institucional: a construção de relacionamento com base em acervos. In: MOURA, C. P. de; MACHADO, M. B. da C. (Org.). Memórias da comunicação: encontros da ALCAR RS, volume II. Porto Alegre: EdiPucRS, 2011. p. 368-378. 
RUEDA, V. M. da S.; FREITAS, A. de; VALLS, V. M. Memória Institucional: uma revisão de literatura. CRB-8 Digital, São Paulo, v. 4, n. 1, p. 78-89, abr. 2011. Disponível em: <http://revista.crb8.org.br/ index.php/crb8digital/article/viewFile/62/64>. Acesso em: 2 maio 2016.

SANTOS, M. A. N. S. Projeto para Instalação de um "Centro de Documentação Histórica". 11 jul. 1980. [Disponível no Acervo do CEHVAP].

SEFFRIN, C.; CAMPO, E.; SCHENKEL, M. B. de C.; SILVA, S. B. da. Gestão de documentos em Arquivos Universitários: Estudo de caso no Arquivo Central da FAED-UDESC. [s. d.]. Disponível em: $<$ http://docplayer.com.br/3137242-Gestao-dedocumentos-em-arquivos-universitarios-estudode-caso-no-arquivo-central-da-faed-udesc.html>. Acesso em: 7 jun. 2016.
SMIT, J. W. Como organizar o arquivo enquanto sistema de informação. São Paulo: Arquivo do Estado de São Paulo, 2005.

VIANA, J. E.; SILVA, R. de P.; PAPALI, M. A.; ZANETTI, V. Memória institucional e Gestão Documental: O Centro de História e Memória da UNIVAP/FVE (CEHVAP). In: XVI ENCONTRO LATINO AMERICANO DE INICIAÇÃO CIENTÍFICA, 16.; XII ENCONTRO LATINO AMERICANO DE PÓS-GRADUAÇÃO, 12., 2012. Anais eletrônicos... São José dos Campos: Universidade do Vale do Paraíba, 2012. Disponível em: <http://www.univap.br/arquivo/ Mem\%C3\%B3ria\%20Institucional\%20e\%20 Gest\%C3\%A3o\%20Documental.pdf?AID=852>. Acesso em: 22 dez. 2016. 